\title{
Research on Mechanical Response of Pavement Structure to Differential Settlement of Subgrade on Highway Widening
}

\author{
Quanjun Shen, ${ }^{1}$ Yu Lu ${ }^{D},{ }^{2}$ Yaohui Yang, ${ }^{1}$ and Guanxu Long ${ }^{1}$ \\ ${ }^{1}$ Shandong Hi-Speed Group Co., Jinan, Shandong 250000, China \\ ${ }^{2}$ School of Civil Engineering, Shandong University, Jinan, Shandong 250000, China \\ Correspondence should be addressed to Yu Lu; luyu_99925@163.com
}

Received 18 August 2021; Accepted 29 November 2021; Published 29 December 2021

Academic Editor: Yongsheng Yao

Copyright ( 2021 Quanjun Shen et al. This is an open access article distributed under the Creative Commons Attribution License, which permits unrestricted use, distribution, and reproduction in any medium, provided the original work is properly cited.

Based on the widening project of Ri-Lan highway in China, the finite element model is established by PLAXIS. By applying differential settlement at the bottom of the pavement, the mechanical response of the pavement structure is analysed. Finally, the differential settlement control standard indicated by crack strength is proposed. The results show that, under the effect of differential settlement, within about $4 \mathrm{~cm}$ of old pavement surface and upper base bear tensile stress, the base first reaches the failure strength. Under $4 \mathrm{~cm}$ of the old pavement surface, the subbase first reaches the failure strength. The differential settlement control standard of the pavement structure is determined by the splitting strength of the material, and we, respectively, control the differential settlement of less than $23.4 \mathrm{~mm}$, where the corresponding cross-slope rate is $0.33 \%$, and below $75.2 \mathrm{~mm}$, where the corresponding cross-slope rate is $0.54 \%$. It could support practical engineering applications.

\section{Introduction}

In order to deal with the problem between the highway capacity and service level, the highway has entered an era of parallel construction and reconstruction and expansion. At present, the experience of highway expansion project shows that if the new subgrade construction method is unreasonable, the differential settlement control standards are not perfect, it will cause the top settlement of the subgrade, and then it will cause the longitudinal cracking of the pavement. Then it affects the use performance of the pavement, serious subgrade collapse, and other road disasters. The force deformation characteristics of highway construction and expansion are different, mainly manifested in the different consolidation degree of the foundation under the new and old subgrade of the highway reconstruction and expansion project, which will cause the differential settlement of the foundation, and then reflected in the top surface of the subgrade, and eventually cause the longitudinal cracking of the road surface. The highway widening project is more difficult with higher quality requirements than the new highway and lacks a more in-depth understanding of the formation mechanism and treatment technology of all kinds of diseases.

At present, the differential settlement control standard of highway widening engineering is mainly considered from structural and functional requirements and by numerical simulation. By establishing elastic-plastic finite element model of pavement, subgrade, and foundation interaction, Yang et al. [1] analysed the mechanical response of pavement structure under postengineering differential settlement and put forward the differential settlement control standard of bilateral widening projects. The results show that different settlement curves of different forms have saddle-shaped distribution, and the postengineering slope rate shall not exceed $0.3 \%$ and $0.45 \%$ during inverted bell distribution. By establishing finite element model to calculate the internal force of pavement structure, Ye et al. [2] proposed that the variation of lateral slope change rate of $0.55 \%$ should be taken as the differential settlement control standard for the single-side widening project of Fo-Kai Expressway. Relying on the Shanghai-Nanjing Expressway reconstruction project, Zhang [3] established the finite element model of new and old road surface through ABAQUS and determined the 
differential settlement control standard from the functional and structural aspects. The result is that the horizontal slope rate is below $0.5 \%$. The structural index required the old horizontal slope rate of the construction road below $0.25 \%$, and below $0.2 \%$. Zhao et al. [4-6] relied on the highway widening project, the road structure layer calculation model under the action of vehicle load is established, and the differential settlement control index is proposed to broaden the change rate of some horizontal slope. Relying on the Anxin highway widening project, Zhen et al. [7] studied the differential settlement control standard and graded it by considering the pavement structural requirements and functional requirements. The results show that the maximum slope rate of $0.19 \%$ is the low limit, and the maximum slope rate of $0.43 \%$ is the high limit. Liu et al. [8], combined with the reconstruction and expansion project of Ankang and Pingli secondary highway, used the finite element calculation method to solve the maximum differential settlement value, and the results showed that when the transverse slope rate was less than $0.3 \%$. Then, the pavement structure would not be damaged. Based on the reconstruction and expansion project of Ji-Qing Expressway, Wang [9] proposed the differential settlement control standard by means of numerical simulation and, combined with the typical pavement structure in Shandong Province, drew the conclusion that the maximum allowable slope change rate was $0.11 \% \sim 0.13 \%$. Through the finite element numerical analysis model, Wang [10] adopted the maximum difference settlement and slope change rate as the index. The results showed that the ultimate tensile strength was taken as the damage index. The differential settlement limit of the old pavement is $9.07 \mathrm{~cm}$ and the corresponding horizontal slope rate is $0.66 \%$. The differential settlement limit of new pavement is $0.98 \mathrm{~cm}$. The corresponding horizontal slope rate is $0.07 \%$. Lu [11], combined with the widening project example of Changyu Expressway, used COMSOL finite element software and proposed that the maximum allowable after-working difference settlement value of the pavement structure shall be determined by the maximum tensile strength at the joint.

To sum up, most of the existing studies put forward the corresponding specific different settlement control indicators based on the actual project. Due to the large difference in different foundation and subgrade properties of different projects, the change range of different settlement control indicators is large, which varies between $0.11 \%$ and $0.5 \%$. Therefore, it is difficult to guide the application of the project, and it also needs to be carried out in combination with the actual situation of the Ri-Lan highway reconstruction and expansion project. The old pavement and split width pavement are discussed, respectively, in this paper, based on the calculation results of subgrade top settlement. PLAXIS finite element software is used to analyse the mechanical response of old and new pavement structural layers to differential settlement. Then, the additional stress of each structural layer under different difference settlement is calculated, and furthermore, the differential settlement control standard is proposed taking the split strength as the index.

\section{Analysis of Subgrade Widening Stress and Deformation Characteristics}

2.1. PLAXIS Introduction. PLAXIS is a powerful geotechnical finite element computing software that has been widely used in the finite element analysis of various complex geotechnical projects, including four subroutines of input, calculation, output, and curve, which used together for geotechnical deformation, stability analysis, and coupling analysis. Preprocessing of PLAXIS is completed by an input subroutine, mainly including establishing geometric models, defining load and boundary conditions, dividing grids, defining soil layers and structural units, and setting initial conditions. Postprocessing of PLAXIS is realized by output and curve subroutine. The output of various kinds of stress, strain, and deformation can be set, as well as the stress strain state of the point and the relationship with time.

\subsection{Calculation Model and Mechanical Parameters}

2.2.1. Basic Assumption. Considering the complexity of the actual situation of the project, make the following assumption with little impact on the calculation results:

(1) Embankment is long enough to be strain.

(2) Mohr-Coulomb model is used for Coulomb and foundation soil.

(3) Materials of each layer are homogeneous, continuous, and isotropic.

(4) Pavement load equivalent of $1 \mathrm{~m}$ high filling acts on the subgrade. As a static simulation, the driving load equivalent of $10 \mathrm{kPa}$ uniform load acts on the subgrade.

In order to simulate the early consolidation of the old subgrade, the process of the calculation starts from the filling of the old subgrade. The construction period and operation period of the old road are considered. After the operation, the displacement field of the old subgrade and the stress field are retained as the initial stress state of the widening subgrade calculation to ensure that the settlement value is generated by the widened subgrade. According to the specification, the working life of the new subgrade is 15 years. Subgrade filling rate is one meter per month and the consolidation rate is one meter per month.

2.2.2. Geometric Model. Combined with the actual situation of the widening project, the original subgrade width is $28 \mathrm{~m}$ and the cross section is $42 \mathrm{~m}$. The cross section with subgrade height of $4 \mathrm{~m}$ is selected for finite element calculation and analysis. The slope rate of the new and old subgrade is 1 : 1.5 , and the foundation drainage consolidation is considered. Semisymmetric structure is selected to consider the influence of boundary effect. The foundation calculation width is $60 \mathrm{~m}$ and the depth is $40 \mathrm{~m}$. The boundary constraints of the model are that horizontal displacement is restrained from the left and the right and the bottom of the model is a fixed constraint. The groundwater level line is 
located $3 \mathrm{~m}$ below the foundation surface with permeable boundary and the rest with impermeable boundary. The finite element model and the grid division model are shown in Figures 1 and 2.

2.2.3. Mechanical Parameters of the Foundation and the Subgrade. For average foundation, the compaction degree of subgrade layer in the project is shown in Table 1. $\gamma$ is the natural weight. $\gamma_{\text {sat }}$ is the saturated capacity weight. $e_{0}$ is the initial pore ratio. $E_{s}$ is the modulus of compression. $v$ is Poisson's ratio. $c$ is the cohesive force. $\varphi$ is the internal friction angle. $k$ is the osmotic coefficient (Table 2). Horizontal permeability coefficient and vertical permeability coefficient are the same.

\subsection{Analysis of the Calculation Results}

2.3.1. Transfer Distribution. As shown in Figure 3 (the 15 years after the settlement), the equivalent area of the vertical displacement is roughly inverted bell distribution, and the vertical shift shows a trend from the left to the right of the model. As shown in Figure 4 (the 15 years after the horizontal shift), the filling makes the horizontal displacement to the inside of the highway and the maximum horizontal displacement to the outside of the highway. The maximum displacement of the subgrade slope position to the inside of the inside of the highway is constantly increasing, and the maximum value range also increases.

The vertical displacement of the foundation surface and the top of the subgrade is drawn in Figures 5 and 6. It can be seen that under the action of the new subgrade, the foundation surface is a deep spoon; that is, the vertical displacement from the middle line of the old subgrade to the new subgrade slope toe is increased first. Then, the displacement reaches the maximum value below the new subgrade core. The vertical displacement of the subgrade top surface is a shallow spoon shape. The maximum value appears on the shoulder of the new subgrade, and the curve is the steeper near the splicing point of the new and old subgrade, where the subgrade cross-slope ratio is the maximum. The contrast diagram shows that the difference between the two vertical displacement is not obvious. This is because the old subgrade has been completely compacted after years of operation and the new subgrade was also filled and compacted. According to the stress diffusion principle of the subgrade, the widening subgrade bears significant wheel pressure, and the compression deformation of the new and old subgrade itself is small.

The data drawing in the horizontal displacement cloud map is extracted to Figures 7 and 8. It is seen that the foundation surface is taken at the excavation steps $(x$ is $18.5 \mathrm{~m})$ as the boundary point. The horizontal displacement movement on both sides is the opposite, and the old subgrade area moves to the centre of the old road and the toe of the new subgrade. Here, corresponding measures can be taken to avoid damage of the soil body. As can be seen from Figure 8, the overall top surface of the subgrade moves to the outside of the highway, and the horizontal displacement from the centre of the old subgrade to the outside of the highway gradually increases. At the first inflection point of the curve of the new and old subgrade splicing, after the horizontal displacement has reached the maximum value, the displacement is gradually reduced.

It shows the change curve of horizontal displacement below the old subgrade slope along with the foundation depth (Figure 9). It can be seen that the horizontal displacement direction below the old subgrade slope is different. Within the foundation depth is $5 \mathrm{~m}$, the inside of the road is horizontal, and the outside of the road is within more than $5 \mathrm{~m}$ depth. and the maximum value is near $20 \mathrm{~m}$ below the foundation. It shows the change curve of the horizontal displacement below the new subgrade toe with the foundation depth (Figure 10). It can be seen that the soil body below the new subgrade toe is presented as the whole moves to the outside of the highway, and the maximum horizontal displacement appears at a certain depth below the surface.

2.3.2. Safety Analysis. The safety calculation module in PLAXIS 2D software is calculated in the limit state for 15 years after the subgrade widening. Under the limit state, the plastic area of the subgrade and foundation in the foundation is shown in Figure 11. The red part in the figure is the plastic area, which can intuitively show that the soil reaches the range of shear strength of Mohr-Coulomb. It shows the displacement cloud map of the subgrade under the filling limit. Figure 12 shows that the potential sliding surface is roughly circular arc and close to the area of the plastic area from the shallow foundation, which shows that the treatment of the new and old subgrade joints should be paid attention to closely connect and improve the overall stability of the subgrade.

\section{Mechanical Response of the Pavement Structure to the Differential Settlement}

3.1. Settlement Distribution Form of the Top Surface of the Subgrade. The pavement structure produces additional stress under the action of widening the size of the subgrade differential settlement, and the size of the additional stress is closely related to the settlement curve of the subgrade top surface [12]. Therefore, the mechanical response of the pavement structure to the differential settlement needs to determine the distribution form of the subgrade top surface. The calculation time of the top settlement of the old subgrade is the construction period and 15 years after the work. The previous calculation results show that, under the reconstruction and expansion load, the differential settlement distribution of the old subgrade is a curved basin. The farther the middle line of the old road, the greater the settlement value. The settlement curve of the top surface of the old subgrade is moved below, so that the centre of the old road coincides with the coordinate origin, and is fitted with the quadratic parabolic function (1) [13]. For the subgrade settlement, the calculation time of the width part is 15 years after work, the distribution of the settlement curve on the top surface of the subgrade is basically parabolic, and the 


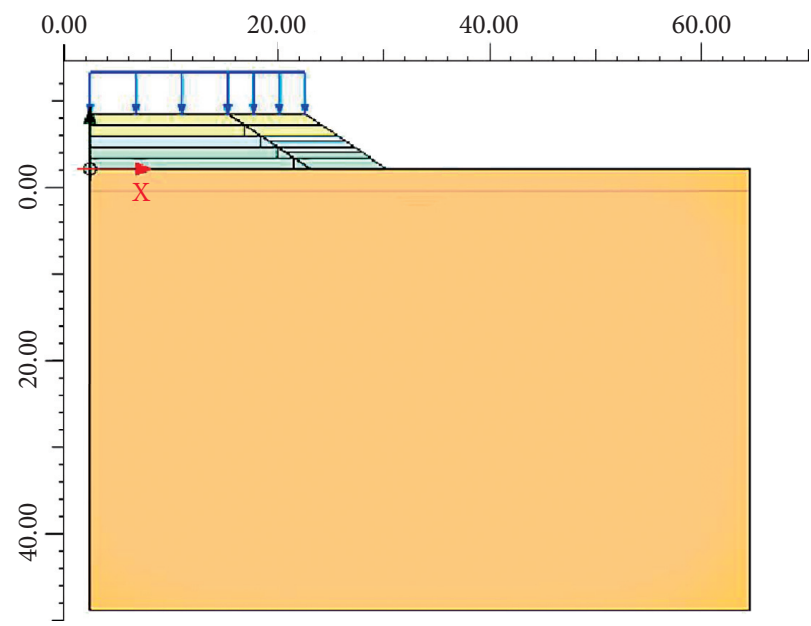

FIgURE 1: Finite element model schematic diagram.

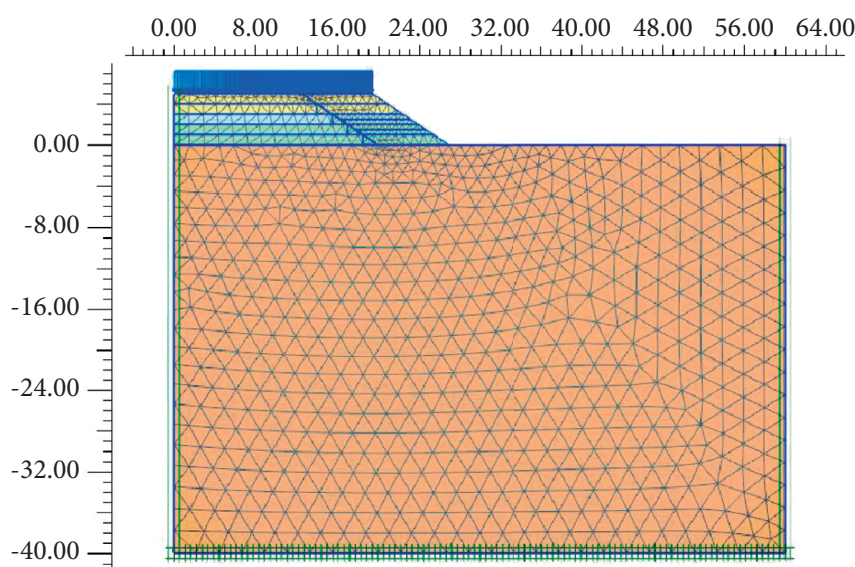

Figure 2: Mesh division model schematic diagram.

TABle 1: Subgrade compaction degree.

\begin{tabular}{lccc}
\hline Fill dig type & & Depth below pavement surface $(\mathrm{cm})$ & Compactness $(\%)$ \\
\hline & Road bed & $0 \sim 30$ & $\geq 97$ \\
Fill with the subgrade & Lower bed & $30 \sim 120$ & $\geq 97$ \\
& Upper embankment & $120 \sim 190$ & $\geq 95$ \\
& Lower embankment & Below 190 & $\geq 94$ \\
\hline
\end{tabular}

TABLE 2: Calculation parameters of foundation and subgrade.

\begin{tabular}{lcccccccc}
\hline Solum & $\gamma\left(\mathrm{kN} / \mathrm{m}^{3}\right)$ & $\gamma_{\text {sat }}\left(\mathrm{kN} / \mathrm{m}^{3}\right)$ & $e_{0}$ & $E_{s}\left(\mathrm{kN} / \mathrm{m}^{3}\right)$ & $\nu$ & $c\left(\mathrm{kN} / \mathrm{m}^{3}\right)$ & $\varphi\left({ }^{\circ}\right)$ & $k(\mathrm{~m} / \mathrm{day})$ \\
\hline Foundation & 17.30 & 19.90 & 0.707 & 7500 & 0.25 & 11.0 & 22.5 & 0.02 \\
District 94 & 1.83 & 20.00 & 0.689 & 13990 & 0.25 & 27.3 & 35.1 \\
District 95 & 1.88 & 20.16 & 0.664 & 15000 & 0.25 & 23.6 & 39.0 \\
District 97 & 1.97 & 20.43 & 0.621 & 16000 & 0.25 & 30.6 & 35.0 & - \\
\hline
\end{tabular}




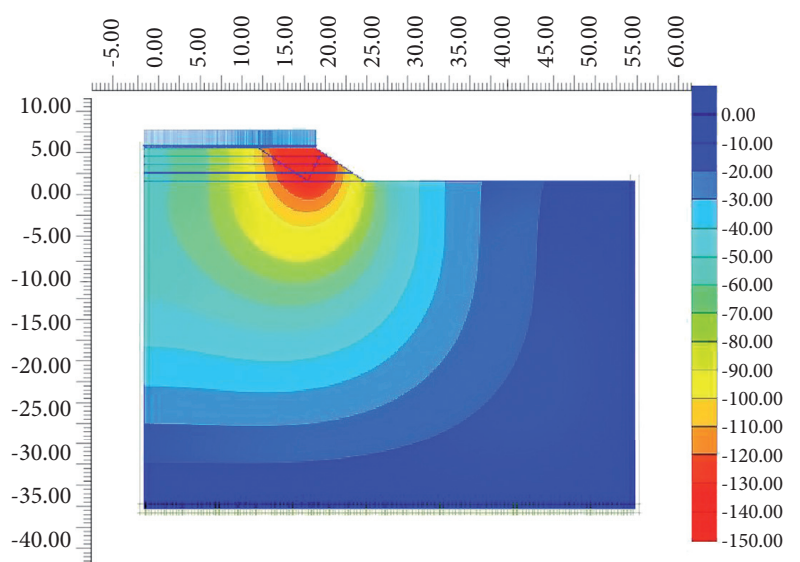

Figure 3: Vertical settlement cloud map.

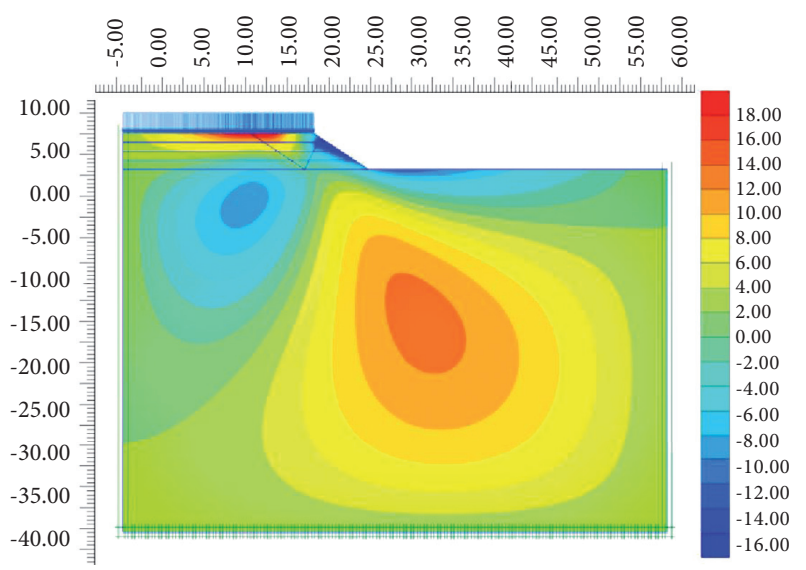

FIgURE 4: Horizontal displacement cloud map.

coordinate origin is also located in the middle point of the old road. The quadratic function (2) is adopted for fitting. The settlement curve of old and new subgrade is shown in Figure 13:

$$
y=-u_{1}\left(\frac{x}{l_{1}}\right)^{2}
$$

where $u_{1}$ is the maximum differential settlement of top surface of old subgrade, and $l_{1}$ is the distance of the old road shoulder to the center of the old road.

$$
y=-u_{1}+u_{2}\left(\frac{1}{l_{2}} x-\frac{l_{1}}{l_{2}}\right)\left(\frac{1}{l_{2}} x-\frac{l_{1}}{l_{2}}-2\right),
$$

where $u_{2}$ is the maximum differential settlement value of the top surface of the widened subgrade, and $l_{2}$ is the maximum differential settlement to the old and new subgrade splicing.

\subsection{Calculation Model and Calculation Parameters.} ABAQUS finite element software is used to calculate the impact of differential settlement of old and new roadbed on the pavement in this chapter [14] (Figure 14). According to the actual situation of Ri-Lan Expressway Reconstruction and Widening Project, the thickness of the pavement is

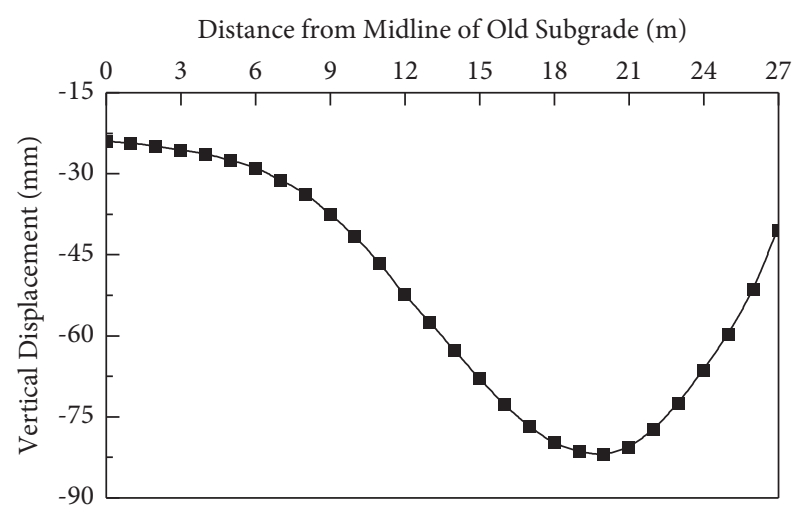

Figure 5: Vertical displacement of ground surface.

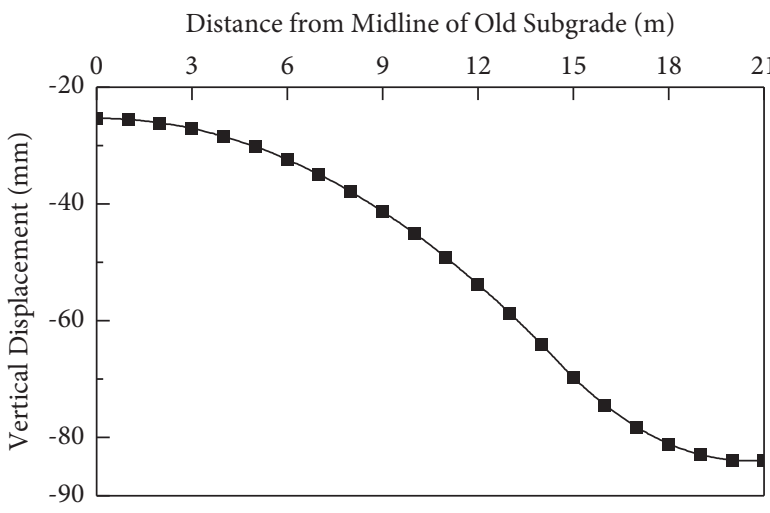

Figure 6: Vertical displacement of subgrade top surface.

$0.84 \mathrm{~m}$. For the finite element model, the model length is $21 \mathrm{~m}$ and the width is $0.84 \mathrm{~m}$. The CPE4 unit is selected for the unit type. The following assumptions are used in the numerical simulation calculations.

(1) The pavement structure is calculated and analysed according to the plane strain problem.

(2) Each layer of the pavement structure is of continuous homogeneous and isotropic linear elastic materials.

(3) The boundary conditions are the vertical displacement applied at the bottom of the model as the settlement fitting function of the subgrade top surface and the left and right boundary horizontal constraints, and the upper boundary is free [15].

The material calculation parameters are calculated according to the pavement structure design documents of Ri-Lan Expressway Reconstruction and Widening Project.

In Table 3 SMA-13 means $3 \mathrm{~cm}$ Stone Mastic Asphalt mixture, $\mathrm{AK}-16$ means $4 \mathrm{~cm}$ medium grain asphalt concrete, AC-20 means $5 \mathrm{~cm}$ medium grain asphalt concrete, and AC30 means coarse graded bituminous concrete. The parameters of the new pavement structure layer are calculated in Table 4.

3.3. Analysis of the Calculation Results. The pavement material has a high compressive strength and low tensile strength. However, the differential settlement caused by the 


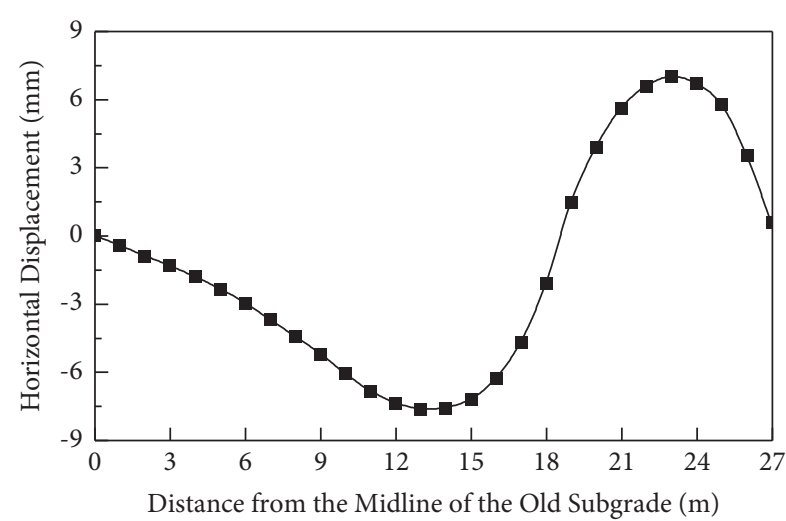

Figure 7: Horizontal displacement of ground surface.

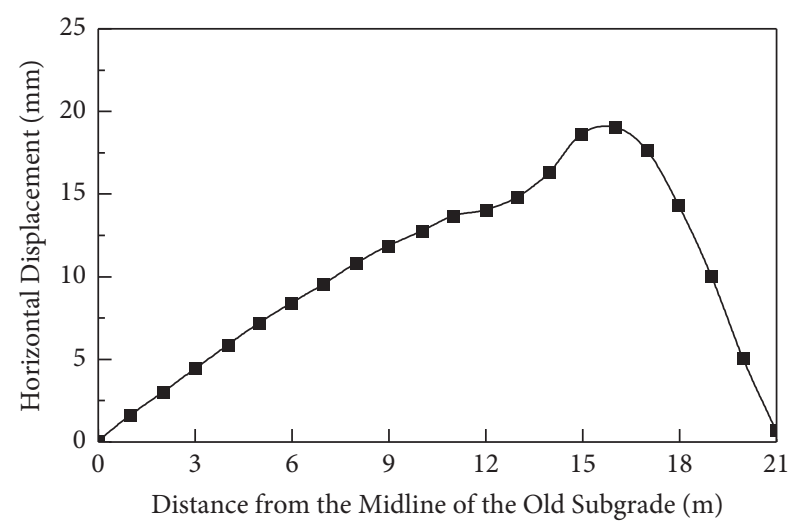

FIgURE 8: Horizontal displacement of subgrade top surface.

highway reconstruction and expansion causes the pavement structure layer to bear the additional bending tensile stress, and the higher tensile stress will make the pavement crack. In this paper, the formula of subgrade top surface settlement curve fitting is incorporated into the subprogram DISP of ABAQUS to specify the displacement of the boundary nodes under the pavement model and then to calculate the additional stress of each pavement structural layer caused by the difference settlement of subgrade top surface.

The additional stress cloud map of the road surface structure is shown in Figure 15. In the direction of the cross section along the road, the differential settlement is gradually increased. Under the action of differential settlement, the old road surface layer and the new road subbase are in the pulled state, the base part is in the pulled state, and the part is in the pressure state. Drawing the horizontal stress data at the top and the bottom of the surface layer and the curve as shown in Figures 16 and 17, we can find that the tensile stress at the top of the surface layer remains basically unchanged within $12 \mathrm{~m}$ from the centre of the old road, then increases slowly, and drops sharply after the peak of the new and old subgrade junction near $13 \mathrm{~m}$, and the compressive stress is within $15 \mathrm{~m}$ to $20 \mathrm{~m}$, which is approximately uniform distribution. The stress curve trend at the bottom of the pavement subbase is contrary to the top of the surface layer, and the tensile stress is reached the maximum at the old and new pavement splices.

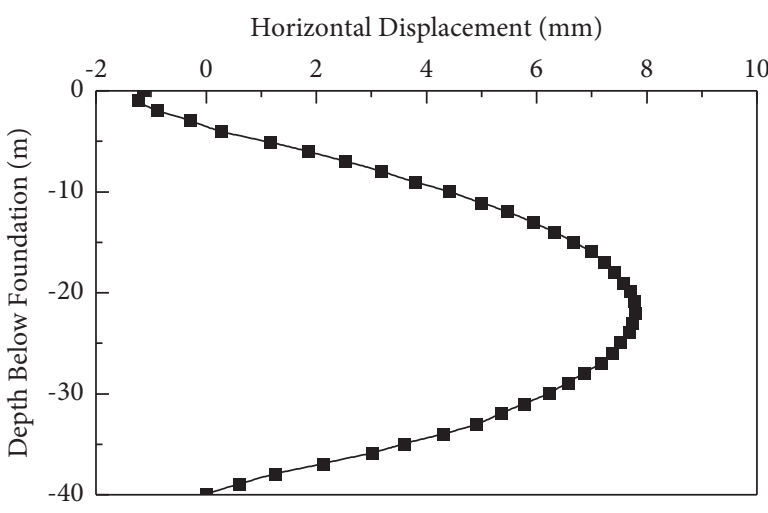

FIgURE 9: Horizontal displacement at the foot of old roadbed slope.

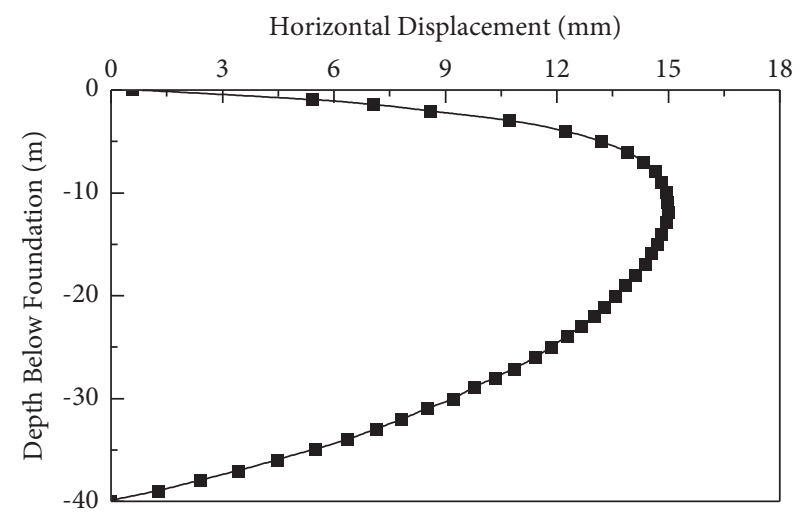

FIGURE 10: Horizontal displacement at foot of new subgrade slope.

The maximum tension stress position at the top and the bottom of the bottom base is drawn along the thickness direction as shown in Figures 18 and 19, and the bottom of the bottom of the bottom is required to consider the old pavement surface layer and the base top and the bottom base layer and the new pavement.

\section{Proposal of the Subgrade Difference Settlement Control Standard}

If the bending tensile capacity of the pavement structure layer shortly after the widening highway is insufficient to resist the additional stress caused by excessive differential settlement, the longitudinal cracks along the highway because the cracks occur in the early operation period called early damage. In this stage, the asphalt pavement periodic traffic load cycle is less and the asphalt is not aging. The bending resistance of the pavement structure layer does not experience fatigue decay. The early damage should be as the control index of the splitting strength of each pavement structural layer [16]. The splitting strength of each layer is shown in Table 5 .

The maximum tensile stress of the old pavement surface layer and base structure layer under the action of different differential settlement are shown in Figure 20. It is found that the maximum additional tensile stress of each layer of the pavement structure is basically linear with the differential 


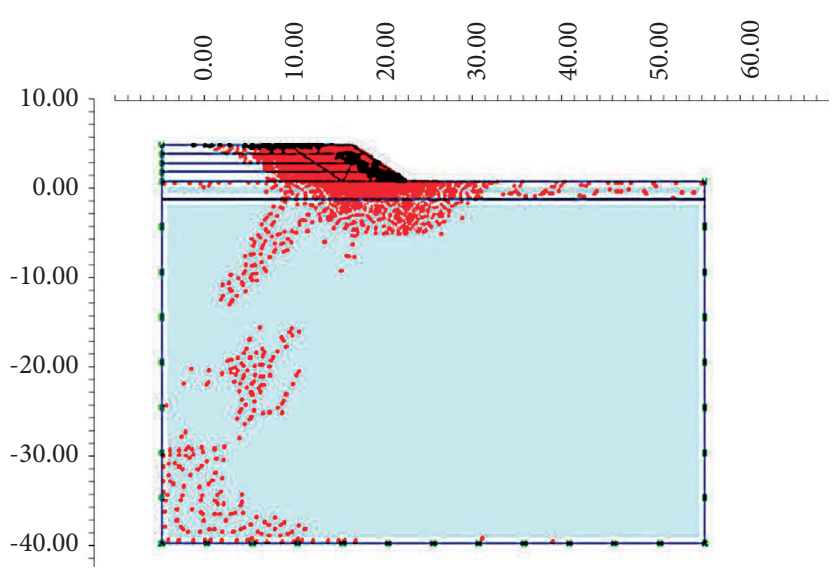

FIgURe 11: Plastic zone in the limit state.

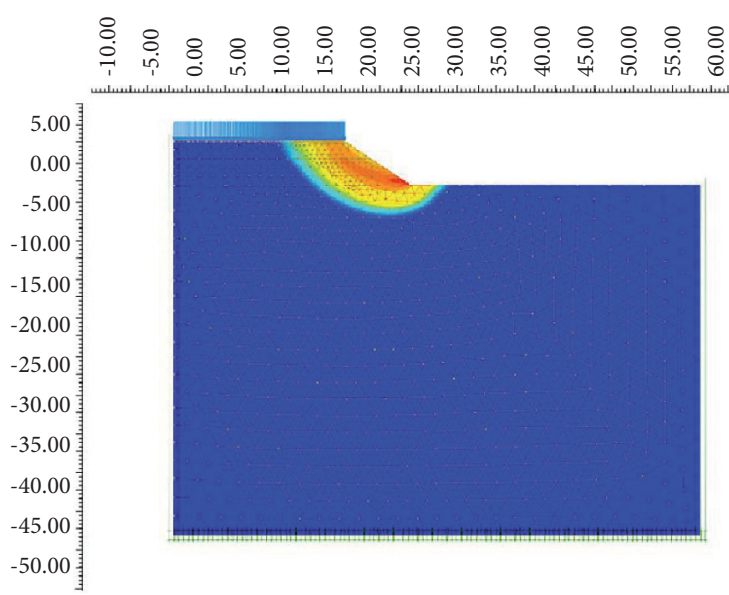

Figure 12: Displacement cloud map in the limit state.

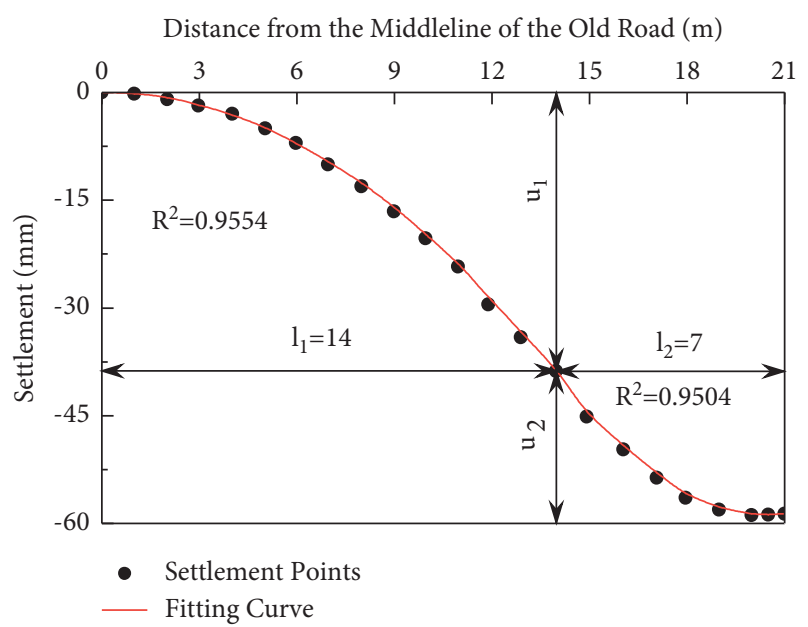

Figure 13: Settlement and fitting curve of the top surface of the subgrade.

settlement, and they show positive correlation. The maximum differential settlement increased from $20 \mathrm{~mm}$ to $80 \mathrm{~mm}$, the maximum additional tensile stress along the old road reinforcement to the secondary gravel layer (base) and the old road reinforcement layer from $0.198 \mathrm{MPa}$ to
$0.932 \mathrm{MPa}$, and the maximum tensile stress of the base from $0.102 \mathrm{MPa}$ to $0.532 \mathrm{MPa}$. The maximum tensile stress of the old base at $80 \mathrm{~mm}$ exceeds $0.532 \mathrm{MPa}$, and the splitting strength is $0.5 \mathrm{MPa}$. The interpolation method can find that when the differential settlement is $75.2 \mathrm{~mm}$, the splitting strength and the surface layer do not reach the splitting strength of the material. Under the same difference settlement, the old base takes the lead in reaching the splitting strength of the material. To sum up, in order to prevent the early cracking and damage of the old pavement, the differential settlement of the old pavement during the widening construction period and the early operation period should be controlled at $0.54 \%$ of the old pavement, which is less than $75.2 \mathrm{~mm}$.

The maximum tensile stress of the new pavement structural layer under different differential settlement is shown in Figure 21, and the new pavement cement-stabilized aggregate layer (base) and low-dose cement-stabilized gravel layer (subbase) are basically positively related to the differential settlement. Under the same differential settlement, the new pavement subbase bears greater tensile stress than the base level, and with the increase of differential settlement, the maximum additional tensile stress change of the subbase is greater. As shown in Table 7, the maximum 
TABLE 3: Calculation parameters of the old pavement structure layer.

\begin{tabular}{lccc}
\hline Pavement structural layer & Thickness $(\mathrm{mm})$ & Modulus of elasticity $(\mathrm{MPa})$ & Poisson's ratio \\
\hline Reinforcing layer of road & 130 & 1600 & 1200 \\
SMA-13 & 30 & 1000 & 0.25 \\
AK-16 & 40 & 1100 & 0.25 \\
AC-20 & 50 & 900 & 0.25 \\
AC-30 & 60 & 1400 & 0.25 \\
Lime-flyash-stabilized base & 350 & 900 & 0.25 \\
Lime flyash soil & 180 & 0.25 \\
\hline
\end{tabular}

TABLE 4: Calculation parameters of the new pavement structure layer.

\begin{tabular}{lccc}
\hline Pavement structural layer & Thickness $(\mathrm{mm})$ & Modulus of elasticity $(\mathrm{MPa})$ & Poisson's ratio \\
\hline SMA-13 & 40 & 1400 & 0.25 \\
AC-20 & 60 & 1200 & 0.25 \\
AC-25 & 80 & 1000 & 0.25 \\
ATB-25 & 100 & 1000 & 0.25 \\
Cement-stabilized aggregate & 360 & 1500 & 0.25 \\
Low dose cement & 200 & 1100 & 0.25 \\
\hline
\end{tabular}

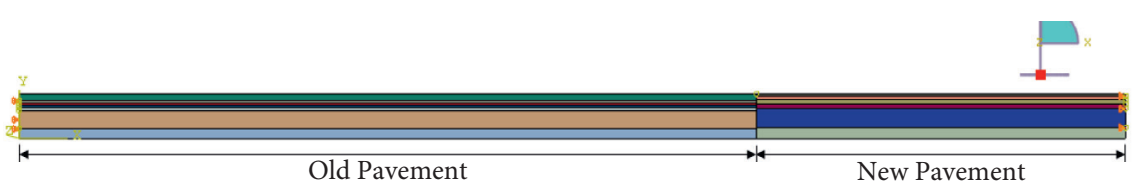

FIGURE 14: Finite element model of pavement structure.

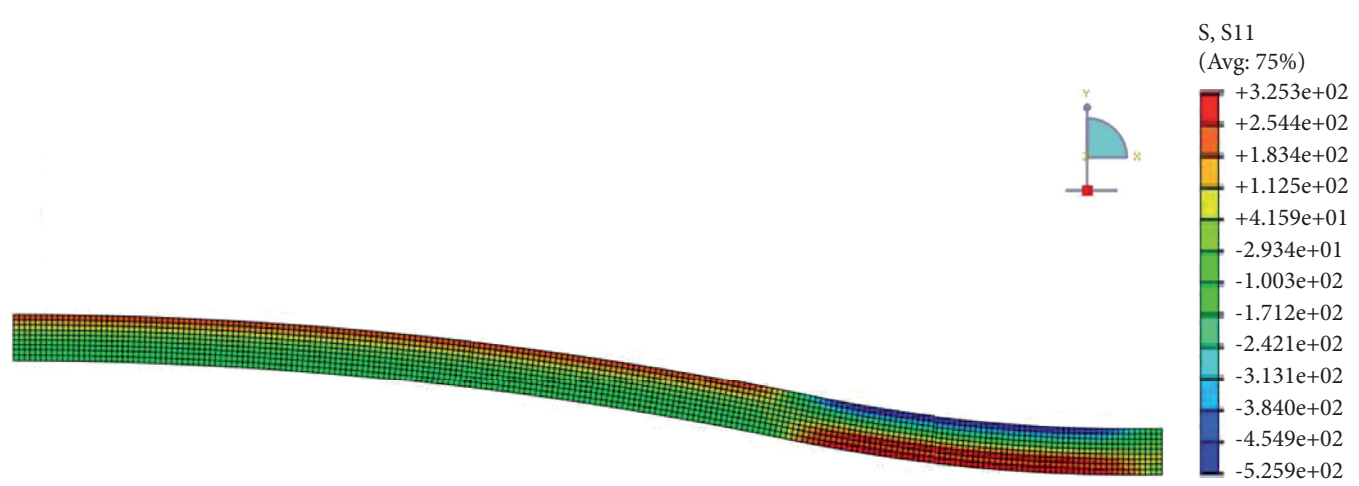

FIGURE 15: Nephogram of additional stress of pavement structure.

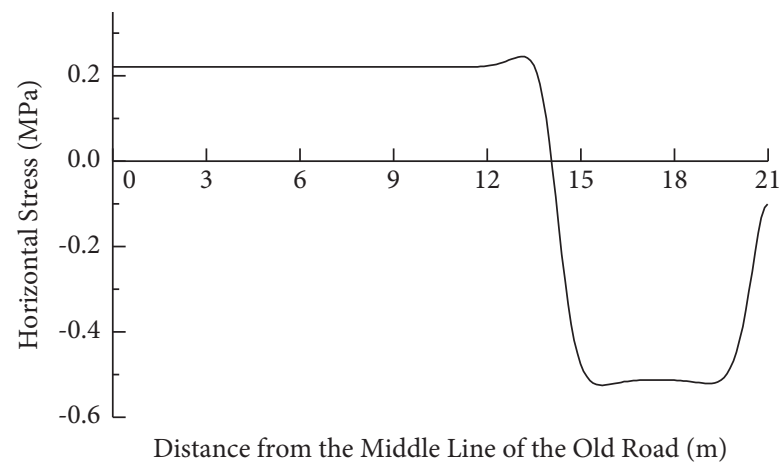

FIgURE 16: Settlement and fitting curve of the top surface of the subgrade. 


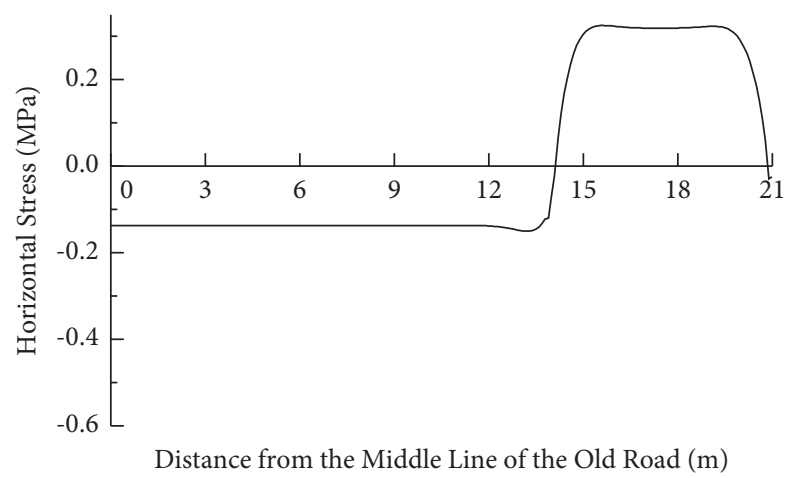

FIgURE 17: Horizontal stress at the bottom of the subbase.

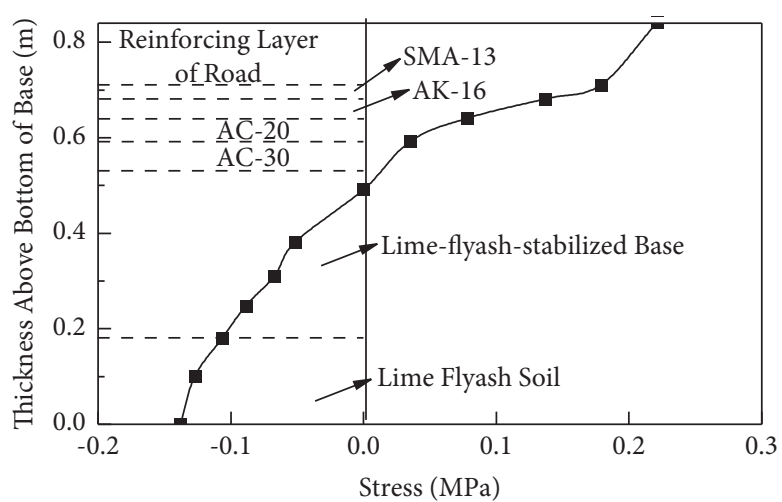

FIgURe 18: Maximum tensile stress position of surface.

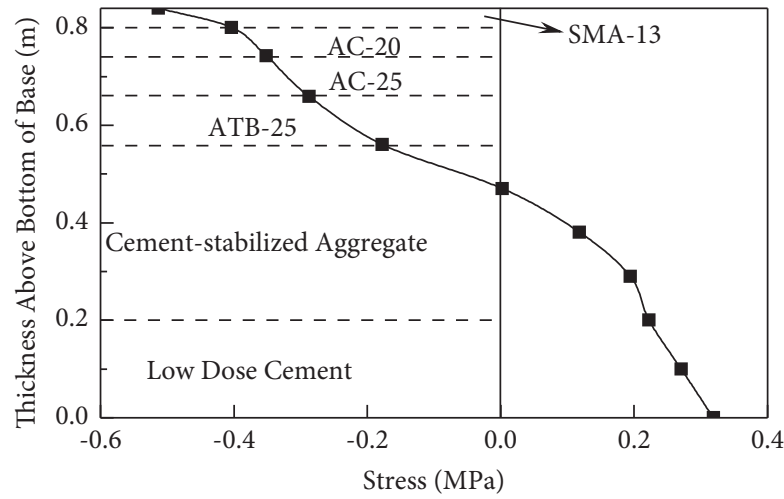

Figure 19: Maximum tensile stress at the bottom of the subbase.

TABLE 5: Splitting strength of the pavement material.

\begin{tabular}{lccc}
\hline Old pavement & Splitting strength $(\mathrm{MPa})$ & New pavement & Splitting strength $(\mathrm{MPa})$ \\
\hline Reinforcing layer of road & 1.4 & Cement-stabilized aggregate & 0.5 \\
SMA-13 & 1.2 & Low dose cement & \\
AK-16 & 1.1 & \\
AC-20 & 1.0 & \\
AC-30 & 0.7 & \\
Lime-flyash-stabilized base & 0.5 & \\
\hline
\end{tabular}

differential settlement increases from $5 \mathrm{~mm}$ to $25 \mathrm{~mm}$. The maximum tensile stress of the base layer increases from $0.042 \mathrm{MPa}$ to $0.225 \mathrm{MPa}$ which is up to the splitting strength of the material. The maximum tensile stress of the subbase is increased from $0.068 \mathrm{MPa}$ to $0.321 \mathrm{MPa}$, and the maximum tensile stress is $0.3 \mathrm{MPa}$, which is up to the splitting strength 


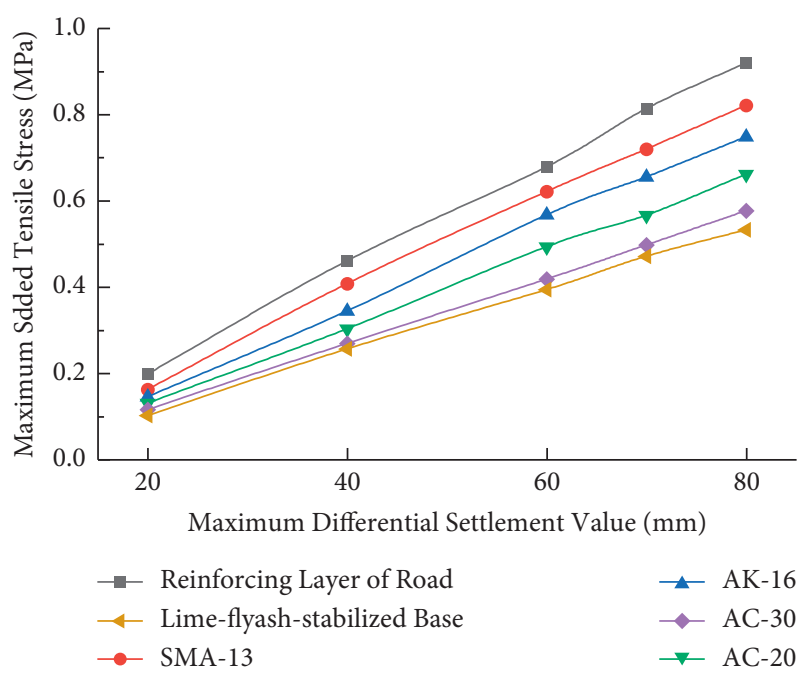

Figure 20: Maximum tensile stress of the old pavement structure layer under different difference settlement.

TABLE 6: Calculation results of maximum tensile stress of structural layer of the old pavement under different differential settlements (MPa).

\begin{tabular}{|c|c|c|c|c|c|}
\hline \multirow{2}{*}{ Pavement structural layer } & \multicolumn{5}{|c|}{ Maximum differential settlement $(\mathrm{mm})$} \\
\hline & 20 & 40 & 60 & 70 & 80 \\
\hline Reinforcing layer of road & 0.198 & 0.461 & 0.678 & 0.814 & 0.932 \\
\hline SMA-13 & 0.162 & 0.407 & 0.622 & 0.720 & 0.821 \\
\hline AK-16 & 0.145 & 0.344 & 0.567 & 0.655 & 0.748 \\
\hline AC-20 & 0.130 & 0.302 & 0.493 & 0.566 & 0.661 \\
\hline AC-30 & 0.115 & 0.269 & 0.418 & 0.497 & 0.577 \\
\hline Lime-flyash-stabilized base & 0.102 & 0.256 & 0.394 & 0.471 & 0.532 \\
\hline
\end{tabular}

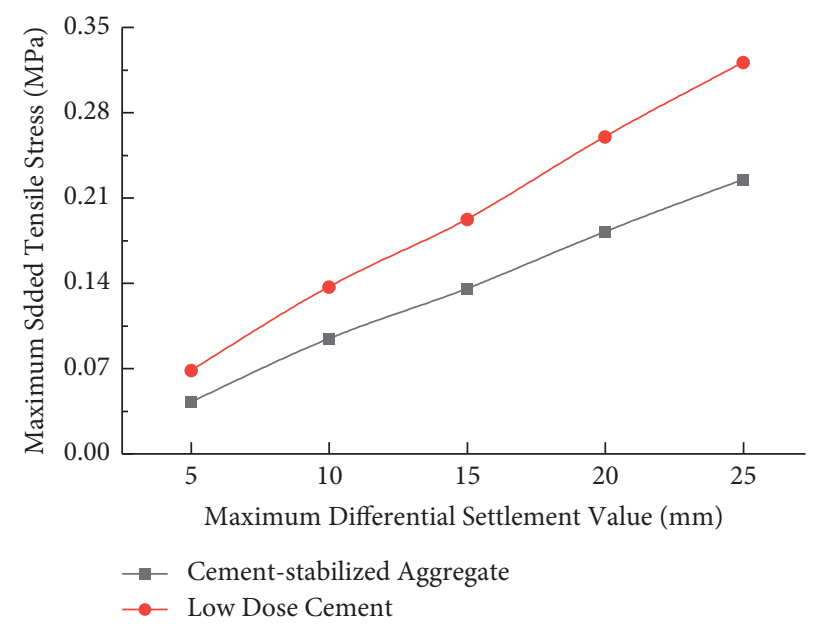

Figure 21: Maximum tensile stress of the new pavement structure layer under different differential settlements.

TABLE 7: Calculation results of maximum tensile stress of the new pavement structure layer under different differential settlements (MPa).

\begin{tabular}{lcccr}
\hline \multirow{2}{*}{ Pavement structural layer } & \multicolumn{4}{c}{ Maximum differential settlement $(\mathrm{mm})$} \\
& 5 & 10 & 15 & 20 \\
\hline Cement-stabilized aggregate & 0.042 & 0.094 & 0.135 & 0.182 \\
Low dose cement & 0.068 & 0.137 & 0.192 & 0.225 \\
\hline
\end{tabular}


when the differential settlement is $23.4 \mathrm{~mm}$ by interpolation. Therefore, to prevent early damage of the new road surface, the differential settlement is less than $23.4 \mathrm{~mm}$, and the horizontal slope rate of the new road surface is $0.33 \%$.

\section{Conclusions}

This paper discusses the new and old pavement separately. Based on the calculation results of subgrade top settlement, the mechanical response of pavement structure under different differential settlement is analysed through the finite element software, and we determined the differential settlement control standard of pavement structure by considering the splitting strength of materials. The specific conclusions are as follows.

(1) Top settlement curve of the new and old subgrade is fitted by quadratic function by applying the fitting results to the bottom of the pavement for calculation. The results showed that the whole surface of the old pavement is about $4 \mathrm{~cm}$ of the upper layer, and the whole bottom layer is about $27 \mathrm{~cm}$ of the lower layer.

(2) Under the action of differential settlement, the old pavement base first reached the damage strength, and the new pavement subbase first reached the damage strength. When the material splitting strength is taken as the control index of the new and old pavement, the differential settlement should be less than $23.4 \mathrm{~mm}$ (cross-slope rate is $0.33 \%$ ), and the horizontal slope rate should be less than $75.2 \mathrm{~mm}$ (cross-slope rate is $0.54 \%$ ).

\section{Data Availability}

The data used to support the findings of this study are included within the article.

\section{Conflicts of Interest}

There are no conflicts of interest regarding the publication of this paper.

\section{Acknowledgments}

This work was supported by the National Key Research and Development Project of China (no. 2018YFB1600100), the Natural Science Foundations of China (nos. 51778346 and 52027813), and the Key Research and Development Project of Shandong Province of China (no. 2019GSF111007).

\section{References}

[1] T. Yang, L. Li, and G. W. Li, "Research on differential settlement control standard for road bilateral widening project," Journal of Highway and Transportation Research and Development, vol. 31, no. 5, pp. 15-20, 2014.

[2] Y. C. Ye, S. Q. Li, and P. Z. Ma, "Study on differential settlement control standard of one-side widening project of Fokai Expressway," Journal of China and Foreign Highway, vol. 33, no. 5, pp. 1-4, 2013.
[3] J. H. Zhang, Research on Deformation Behaviour and Differential Settlement Limitation of Expressway Widening on Soft Soil Foundation, Southeast University, Nanjing, China, 2006.

[4] Q. S. Zhao, G. S. Zhao, and C. H. Zhang, "Threshold of settlement control for widened Jing-Shi embankments," Journal of Liaoning Technical University, vol. 31, no. 1, pp. 69-72, 2012.

[5] J. F. Hua, L. Guo, and H. J. Yu, "Study on subgrade differential Settlement and treatment measures of Changyu Expressway," Highways, vol. 66, no. 1, pp. 370-374, 2021.

[6] S. Zhang, Study on Differential Settlement Characteristic and Control Standards of Subgrade Widening of Yan'an north Transit Line, Chang'an University, Xi'an, China, 2019.

[7] F. Zhen, X. C. Wang, X. G. Chen, and H. Z. Li, "Controlling criterion of differential settlements after widening expressway," Journal of Changan University (Natural Science Edition), vol. 28, no. 5, pp. 10-13, 2008.

[8] H. Q. Liu, G. D. Zeng, and R. H. Ying, "Study on non-uniform settlement index of old road widening after construction," Highways, vol. 3, no. 3, pp. 37-39, 2004.

[9] K. Wang, Research on Deformation Behavior and Control Criterion of Deferential Settlement in Express Highway Widening Project, Shandong University, Jinan, China, 2018.

[10] J. H. Wang, Study on Differential Settlement Characteristics and Control Technology of Subgrade in G320 (Quzhou Section) Reconstruction and Expansion Project, Chang'an University, Xi'an, China, 2017.

[11] X. F. Lu, Study on Differential Settlement Mechanism and Control Standard of Widening Subgrade of Changyu Expressway, Harbin Institute of Technology, Harbin, China, 2016.

[12] Y. Yao, J. Ni, and J. Li, "Stress-dependent water retention of granite residual soil and its implications for ground settlement," Computers and Geotechnics, vol. 129, Article ID 103835, 2021.

[13] Y. Yao, J. Li, J. Ni, C. Liang, and A. Zhang, "Effects of gravel content and shape on shear behaviour of soil-rock mixture: experiment and DEM modelling," Computers and Geotechnics, vol. 141, 2022.

[14] J. H. Zhang, A. S. Zhang, C. Huang, and H. Yu, "Characterising the resilient behaviour of pavement subgrade with construction and demolition waste under Freeze-Thaw cycles," Journal of Cleaner Production, vol. 300, 2021.

[15] J. Han and M. A. Gabr, "Numerical analysis of geosyntheticreinforced and pile-supported earth platforms over soft soil," Journal of Geotechnical and Geoenvironmental Engineering, vol. 128, no. 5, pp. 44-53, 2002.

[16] Z. Fu, Study on the Differential Settlement and Controlling Technology of Expressway Widening Subgrade, Chang'an University, Xi'an, China, 2007. 